\title{
Effect of Balloon Inflation and Cough Trick Methods on Pain Intensity During Venipuncture Among Children
}

\author{
Nahed K. Mohammed ${ }^{1}$, Eman S. Ahmed ${ }^{2}$, Mohammed A. Fathy ${ }^{3}$ \& Nora A. Zaki ${ }^{4}$. \\ 1. Assistant lecturer in Pediatric Nursing Department, Faculty of Nursing, Assuit University, Egypt. \\ 2. Professor of Pediatric Nursing, Faculty of Nursing, Assuit University, Egypt. \\ 3. Professor of Pediatrics, Faculty of Medicine ,Assuit University, Egypt. \\ 4. Assistant Professor of Pediatric Nursing, Faculty of Nursing, Assuit University, Egypt.
}

\begin{abstract}
Background:- Venipuncture is the commonest painful invasive procedures that usually applied for children, this process keep the children stressful and frightening. So this study aimed to examine the effects of balloon inflation and cough trick method on pain intensity during venipuncture among children. A quasi experimental design was used in this study. Subjects included 90 school age children were recruited from emergency unit as well as medical and hematology units in Assuit University Children's Hospital. They were selected randomly and divided into three groups: balloon inflation group, cough trick group and control group. Two tools were used for gathering necessary data which were a structured questionnaire and Facial Pain Scale- Revised (FPS- R scale). Results of the present study revealed that the majority of studied children have mild pain in study group I \& II and more than two thirds have moderate pain in control group, both methods of intervention were effective in pain relief (p-value $\leq 0.000$ ), but balloon inflation was slightly better. Conclusion balloon inflation and cough trick were effective in reducing pain intensity during venipuncture. Therefore, it is recommended to use an educational training program for nurses about using balloon inflation and cough trick as non- pharmacological intervention to reduce pain among children
\end{abstract}

\section{Keywords: Balloon Inflation, Children, Cough trick, Pain intensity \& Venipuncture.}

\section{Introduction}

Pain perception in children is intricate and children frequently undergo medical procedures that are applied using a needle, such as venipuncture and immunization which considered the most common sources of pain for children causes considerable stress and anxiety for children and their parents (Anand \& Craig, 2014).

Venipuncture is one of the most widely used diagnostic and therapeutic procedures in children. Analgesia through venipuncture may be efficiently achieved with distracting techniques. The simple insertion of a needle has been exposed to be one of the most frightening and distressing medical procedures for hospitalized children. Additionally, fear of pain experienced due to medical procedures in childhood usually remains up to adulthood (McGrath \& Frager, 2017).

There are two types of pain treatment, the pharmacological and non-pharmacological treatment. Pharmacological intervention involves the administration of drugs for pain relief. Non pharmacological intervention include controlled breathing, virtual reality, guided relaxation, interactive toys, electronic games, auditory techniques like music and audiovisual techniques like television, balloon inflation and cough trick methods (Algren \& Goldman, 2012).
Balloon inflation was a physiological effect which causes reduction in venous return with increased intrathoracic pressure. It has been speculated that this increase in pressure induces baroreceptor activation with contraction of the pulmonary vessels, and that the activation of cardiopulmonary and Sino aortic baroreceptor reflex arcs has an ant nociceptive effect, resulting in pain relief (Mutlu \& Balcı, 2015).

Coughing increases intrathoracic pressure and stimulation to the autonomic nervous system, causing an increase in heart rate and blood pressure, a higher level of pressure in the subarachnoid space, and baroreceptor activation. The increase in pressure in the subarachnoid space activates the segmental pain inhibiting pathways; thus, the increase in blood pressure and baroreceptor activation appears to be efficacious in reducing the perception of pain (Wallace \& Allen, 2015).

Nurses acting a key role in identifying causes of pain, minimizing exposure to painful medical procedures, proactively assessing and treating pain and have a responsibility to reduce pain and anxiety as much as possible while conserving children safety. Also, teaching the child and family about non pharmacologic methods of pain management, and reduction of pain by applying comfort measure. Also, the nurses have essential role in evaluating the efficacy of treatment methods by paralleling pre and 
post treatments and watching for the side effects frequently (American Academy of pediatrics (AAP), 2011). Home were, It is important to assist the child and their parents when using the technique in order to make sure that they are using the technique correctly (Sukhomlinova \& Tichonovskay, 2013).

\section{Significance of the study}

Recent years, many children have been exposed to diagnostic or therapeutic measures which create different levels of pain. WHO and several pediatric societies supporter improving the approach to pain in children in a medical environment. Venipuncture is one of the most painful invasive procedures that are frequently used in hospitalized children, because this method is the basis and introduction in the diagnosis and treatment of most children's diseases. Lack of pain relief during invasive procedures will have serious negative consequences especially when the pain is caused by needle insertion. Children's memory and recalling painful procedure will lead to severe psychological and physiological responses during the subsequent experiences of the child (Sukhomlinova \& Tichonovskay, 2013). Coughing and inflating balloons during venipuncture do not require preparation and easy to be learnt to children to reduce pain.

\section{Aim of the Study}

This study aimed to examine the effect of balloon inflation and cough trick on pain among children during drawing of venous blood samples.

\section{Research hypotheses}

1- Children in the study group who inflate balloon and use cough trick method have less pain intensity than those who are in control group during venipuncture procedure.

2- There are a difference in pain intensity among children by application of balloon inflation and cough trick methods.

\section{Subjects and Method \\ Research Design :}

Quasi experimental research design was utilized in

this study.

Setting

This study was conducted at emergency unit as well as medical and hematology units in Assiut University Children Hospital.

\section{Subjects}

A simple random sample was used in this study. The study included 90 school age children of both genders, they were divided randomly into three groups 30 children for each group. Complete randomization was done by using closed envelope method which done as the following technique, the researcher using 90 pieces of paper, balloon group was written in 30 pieces, cough trick group was written in 30 pieces and finally control group was written in last 30 pieces where pieces were placed in a box and then one piece of paper is randomly chosen by every child in the study, eventually, 30 children inflate the balloon, 30 children used cough trick method and other 30 children received no intervention.

\section{Power analysis}

A power calculation was estimated in order to detect an effect size of 3.27 difference of pain score between means of two independent groups, with a p-value < 0.05 and $80 \%$ power, confidence level 0.95 , a sample size of 26 children for each group was needed. However, 30 children in each group were attempted in this research work to avoid non-response rate. This calculated using G Power 3.1 (Hsieh, 1998).

Inclusion criteria included:

- School age children from 6-12 years old.

- The score of pain before venipuncture was zero..

- Children who didn't receive analgesic and hypnotic before intravenous insertion

Exclusion criteria included:

- Children who had taken analgesic drugs within 24 hours prior to blood sampling procedure.

- Children with fever, respiratory disorders, a medical history of fainting, or chronic diseases that causes pain.

Tools of data collection

Two tools were used to collect the required data for this study

\section{Tool (1): A structured questionnaire}

It was developed by the researchers to collect the required information and it included the following two parts :-

Part (1): Personal data of studied children and their parents such as (age, residence, gender, birth order, care giver attendance, parents'education and occupation).

Part (2): Data related to venipuncture procedure of studied children such as how much time had elapsed since the last blood sample was taken, venipuncture site, size of syringe, success of venipuncture, related problems in site of venipuncture, type of health problem, cause of hospital admission, previous hospitalization, and whether or not the child had a fear of needles.

Tool (II) Facial Pain Scale-Revised (FPS-R).

It was developed by Nilsson et al., (2008), to assess pain in children aged 4-18 years. It consisted of six facial expressions that evaluate the degree of pain, on a scale of 0-10. Each face has score $(0,2,4,6,8$, 10) from left to right. Its score ranged from zero (no pain) to ten (sever pain).

Scoring system of FPS-R scale 
$0=$ no pain

$2,4=$ mild pain

$6,8=$ moderate pain

$10=$ sever pain

Method of data collection

- An official permission was obtained from the director of units, and also obtained from the director of Assiut University Children Hospital.

- Validity of tool one was tested by jure of 5 experts in pediatric nursing field and Content Validity Index (CVI) was calculated and its results was $95 \%$

- Reliability for tool one was estimated by Alpha Cronbach's test and its result was $\mathrm{r}=0.68$

- A pilot study was carried out on $10 \%$ (9) of the sample. The aim of the pilot study was to test the clarity and applicability of the tools and to estimate time needed to fulfill each sheet and the final form was developed. The children were included in the total sample.

- Tool one was developed by the researcher after reviewing literature

- Tool two was valid and reliable (Francesco et al., 2013), it was ( $\mathrm{r}=0.7)$

Field of the work

This study was carried out through a period of seven months from the beginning of April (2018) to the end of October (2018). The researcher went to hospital two days per week from 8 am to 10 am to enroll the children from emergency unit as well as medical and hematology unit in the hospital. After explaining the aim and nature of the study to the parents of studied children, a written parents' consent was obtained for participation of their children in the study. The time needed for every child was 20 minutes (10 minutes for applying intervention and 10 minutes for filling questionnaire using parent and child's sheet.

\section{Intervention}

- Balloon inflation: In the study group (1), the school age children were asked to choose a balloon of the color of their choice and then children is inflated balloon during the venipuncture procedure. During procedure, Children were video recorded for 2 minutes in order to identify the face of the child and compare the child's face with the aspect of FPS-R. The video recording were interpreted by the researcher and the total score of pain was calculated.

- Cough trick: In the study group (II), the school age children were asked before the procedure to take a deep breath and cough actively during venipuncture and also Children were video recorded for 2 minutes in order to identify the face of the child and compare the child's face with the aspect of FPS-R and repeat the technique used in balloon group.

- The control group: group (III), children in the control group experienced routine pain intervention measures but they were allowed to play with balloon to prevent sample bias (sham intervention).

\section{Ethical Considerations}

Written informed consent was taken from parents of each child participating in the study and they are secured that data will be confidential and used only for the research purpose. The parents had the right to withdraw their children from the study at any time without any effect on the care provided for their children.

\section{Statistical analysis}

Data entry and data analysis were done using SPSS (Statistical Package for Social Science) version 19. Data were presented as number, percentage, mean and standard deviation. Chi-square test and Fisher exact test were used to compare qualitative variables. Independent samples t-test was used to compare quantitative variables in case of parametric data and Mann-Whitney test was used to compare between quantitative variables in case of non parametric data. $\mathrm{P}$-value was considered statistically significant when $\mathrm{P}<0.05$. 


\section{Results}

Table (1): Personal data of the studied children $(n=90)$.

\begin{tabular}{|c|c|c|c|c|c|c|c|}
\hline \multirow[t]{2}{*}{ Personal data } & \multicolumn{2}{|c|}{$\begin{array}{l}\text { Study group I Balloon } \\
\text { Inflation group }(n=30)\end{array}$} & \multicolumn{2}{|c|}{$\begin{array}{c}\text { Study group II Cough } \\
\text { trick group }(n=30)\end{array}$} & \multicolumn{2}{|c|}{$\begin{array}{c}\text { Control group } \\
(\mathbf{n}=\mathbf{3 0})\end{array}$} & \multirow[t]{2}{*}{ P-value } \\
\hline & No. & $\%$ & No. & $\%$ & No. & $\%$ & \\
\hline \multicolumn{7}{|l|}{ Gender } & \multirow{3}{*}{0.731} \\
\hline Male & 14 & 46.7 & 12 & 40.0 & 15 & 50.0 & \\
\hline Female & 16 & 53.3 & 18 & 60.0 & 15 & 50.0 & \\
\hline \multicolumn{7}{|l|}{ Age in years } & \multirow{4}{*}{0.245} \\
\hline $6-<8$ & 17 & 56.7 & 19 & 63.3 & 21 & 70.0 & \\
\hline $8-<10$ & 13 & 43.3 & 8 & 26.7 & 7 & 23.3 & \\
\hline $10-12$ & 0 & 0.0 & 3 & 10.0 & 2 & 6.7 & \\
\hline Mean \pm SD & \multicolumn{2}{|c|}{$7.20 \pm 1.10$} & \multicolumn{2}{|c|}{$7.33 \pm 1.42$} & \multicolumn{2}{|c|}{$7.23 \pm 1.41$} & \\
\hline Range & \multicolumn{2}{|c|}{$7.0(6.0-9.0)$} & \multicolumn{2}{|c|}{$7.0(6.0-11.0)$} & \multicolumn{2}{|c|}{$7.0(6.0-11.0)$} & \\
\hline \multicolumn{7}{|l|}{ Birth order } & \multirow{4}{*}{0.364} \\
\hline First & 10 & 33.3 & 8 & 26.7 & 14 & 46.7 & \\
\hline Second & 16 & 53.3 & 14 & 46.7 & 12 & 40.0 & \\
\hline Third & 4 & 13.4 & 8 & 26.7 & 4 & 13.3 & \\
\hline \multicolumn{7}{|l|}{ Residence } & \multirow{3}{*}{0.821} \\
\hline Urban & 21 & 70.0 & 19 & 63.3 & 19 & 63.3 & \\
\hline Rural & 9 & 30.0 & 11 & 36.7 & 11 & 36.7 & \\
\hline \multicolumn{7}{|c|}{ parents' attendance during venipuncture } & \multirow{3}{*}{$0.010 *$} \\
\hline Mother & 22 & 73.3 & 26 & 86.7 & 30 & $\mathbf{1 0 0 . 0}$ & \\
\hline Father & 8 & 26.7 & 4 & 13.3 & 0 & 0.0 & \\
\hline
\end{tabular}

Table (2): Percentage distribution of studied children regarding to their data related to venipuncture procedure $(\mathbf{n}=90)$.

\begin{tabular}{|c|c|c|c|c|c|c|c|c|c|}
\hline \multirow[t]{2}{*}{ Venipuncture procedure } & \multicolumn{2}{|c|}{$\underset{\mathbf{n}=\mathbf{3 0}}{\text { Study group I }}$} & \multicolumn{2}{|c|}{$\begin{array}{c}\text { Study group II } \\
\mathbf{n = 3 0}\end{array}$} & \multicolumn{2}{|c|}{$\begin{array}{c}\begin{array}{c}\text { Control group } \\
\mathbf{n}=\mathbf{3 0}\end{array} \\
\text {. }\end{array}$} & \multirow[t]{2}{*}{ P-value ${ }^{1}$} & \multirow[t]{2}{*}{ P-value ${ }^{2}$} & \multirow[t]{2}{*}{ P-value ${ }^{3}$} \\
\hline & No. & $\%$ & No. & $\%$ & No. & $\%$ & & & \\
\hline \multicolumn{7}{|c|}{ Time elapsed since the last blood sample/ months } & \multirow{5}{*}{0.543} & \multirow{5}{*}{$0.016 *$} & \multirow{5}{*}{0.294} \\
\hline $1-<4$ & 3 & 10.0 & 6 & 20.0 & 11 & 36.7 & & & \\
\hline $4-<8$ & 12 & $\mathbf{4 0 . 0}$ & 8 & 26.7 & 5 & 16.7 & & & \\
\hline $8-<12$ & 9 & 30.0 & 8 & 26.7 & 4 & 13.3 & & & \\
\hline 1 year or more & 6 & 20.0 & 8 & 26.7 & 10 & 33.3 & & & \\
\hline \multicolumn{7}{|l|}{ Venipuncture site } & \multirow{6}{*}{0.076} & \multirow{6}{*}{$0.010 *$} & \multirow{6}{*}{0.228} \\
\hline Basilic vein & 15 & 50.0 & 18 & 60.0 & 11 & 36.7 & & & \\
\hline Cephalic vein & 6 & 20.0 & 5 & 16.7 & 10 & 33.3 & & & \\
\hline Dorsal metacarpal vein & 7 & 23.3 & 1 & 3.3 & 0 & 0.0 & & & \\
\hline Median cubital vein & 0 & 0.0 & 0 & 0.0 & 1 & 3.3 & & & \\
\hline Redial vein & 2 & 6.7 & 6 & 20.0 & 8 & 26.7 & & & \\
\hline \multicolumn{7}{|l|}{ Size of syringe } & \multirow{3}{*}{1.000} & \multirow{3}{*}{0.472} & \multirow{3}{*}{0.488} \\
\hline $3 \mathrm{~cm}$ & 27 & 90.0 & 26 & 86.7 & 24 & 80.0 & & & \\
\hline $5 \mathrm{~cm}$ & 3 & 10.0 & 4 & 13.3 & 6 & 20.0 & & & \\
\hline \multicolumn{7}{|l|}{ Success of venipuncture } & \multirow{3}{*}{0.243} & \multirow{3}{*}{0.371} & \multirow{3}{*}{0.781} \\
\hline $1^{\text {st }}$ time & 24 & 80.0 & 20 & 66.7 & 21 & 70.0 & & & \\
\hline $2^{\text {nd }}$ time & 6 & 20.0 & 10 & 33.3 & 9 & 30.0 & & & \\
\hline \multicolumn{7}{|c|}{ Related problem in site of venipuncture } & \multirow{3}{*}{0.781} & \multirow{3}{*}{0.067} & \multirow{3}{*}{0.117} \\
\hline Yes & 10 & 33.3 & 9 & 30.0 & 4 & 13.3 & & & \\
\hline No & 20 & 66.7 & 21 & 70.0 & 26 & 86.7 & & & \\
\hline \multicolumn{7}{|l|}{ Type of problem } & \multirow{4}{*}{0.711} & \multirow{4}{*}{0.680} & \multirow{4}{*}{0.575} \\
\hline Redness & 6 & 60.0 & 4 & 44.4 & 2 & 50.0 & & & \\
\hline Hematoma & 1 & 10.0 & 2 & 22.3 & 0 & 0.0 & & & \\
\hline Bleeding & 3 & 30.0 & 3 & 33.3 & 2 & 50.0 & & & \\
\hline
\end{tabular}


Table (2): Cont: percentage distribution of studied children regarding to their data related to venipuncture procedure $(\mathbf{n}=90)$.

\begin{tabular}{|c|c|c|c|c|c|c|c|c|c|}
\hline \multirow[t]{2}{*}{ Venipuncture procedure } & \multicolumn{2}{|c|}{$\begin{array}{c}\text { Study group I } \\
\mathbf{n}=\mathbf{3 0}\end{array}$} & \multicolumn{2}{|c|}{$\begin{array}{l}\text { Study group II } \\
\qquad \mathbf{n = 3 0}\end{array}$} & \multicolumn{2}{|c|}{$\begin{array}{c}\text { Control group } \\
\mathbf{n}=\mathbf{3 0}\end{array}$} & \multirow[t]{2}{*}{ P-value ${ }^{1}$} & \multirow[t]{2}{*}{ P-value ${ }^{2}$} & \multirow[t]{2}{*}{ P-value ${ }^{3}$} \\
\hline & No. & $\%$ & No. & $\%$ & No. & $\%$ & & & \\
\hline \multicolumn{7}{|l|}{ Cause of hospital admission } & \multirow{4}{*}{0.327} & \multirow{4}{*}{0.259} & \multirow{4}{*}{0.733} \\
\hline Blood diseases & 11 & 36.7 & 12 & 40.0 & 15 & 50.0 & & & \\
\hline Endocrine diseases & 6 & 20.0 & 10 & 33.3 & 8 & 26.7 & & & \\
\hline Gastrointestinal diseases & 13 & 43.3 & 8 & 26.7 & 7 & 23.3 & & & \\
\hline \multicolumn{7}{|l|}{$\begin{array}{l}\text { Previous hospitalization } \\
\end{array}$} & \multirow{3}{*}{0.317} & \multirow{3}{*}{$0.005^{*}$} & \multirow{3}{*}{0.058} \\
\hline Yes & 26 & 86.7 & 23 & 76.7 & 16 & 53.3 & & & \\
\hline No & 4 & 13.3 & 7 & 23.3 & 14 & 46.7 & & & \\
\hline \multicolumn{7}{|c|}{ Fear of needles due to hospitalization } & \multirow{3}{*}{1.000} & \multirow{3}{*}{1.000} & \multirow{3}{*}{--} \\
\hline Yes & 25 & 96.2 & 23 & 100.0 & 16 & 100.0 & & & \\
\hline No & 1 & 3.8 & 0 & 0.0 & 0 & 0.0 & & & \\
\hline
\end{tabular}

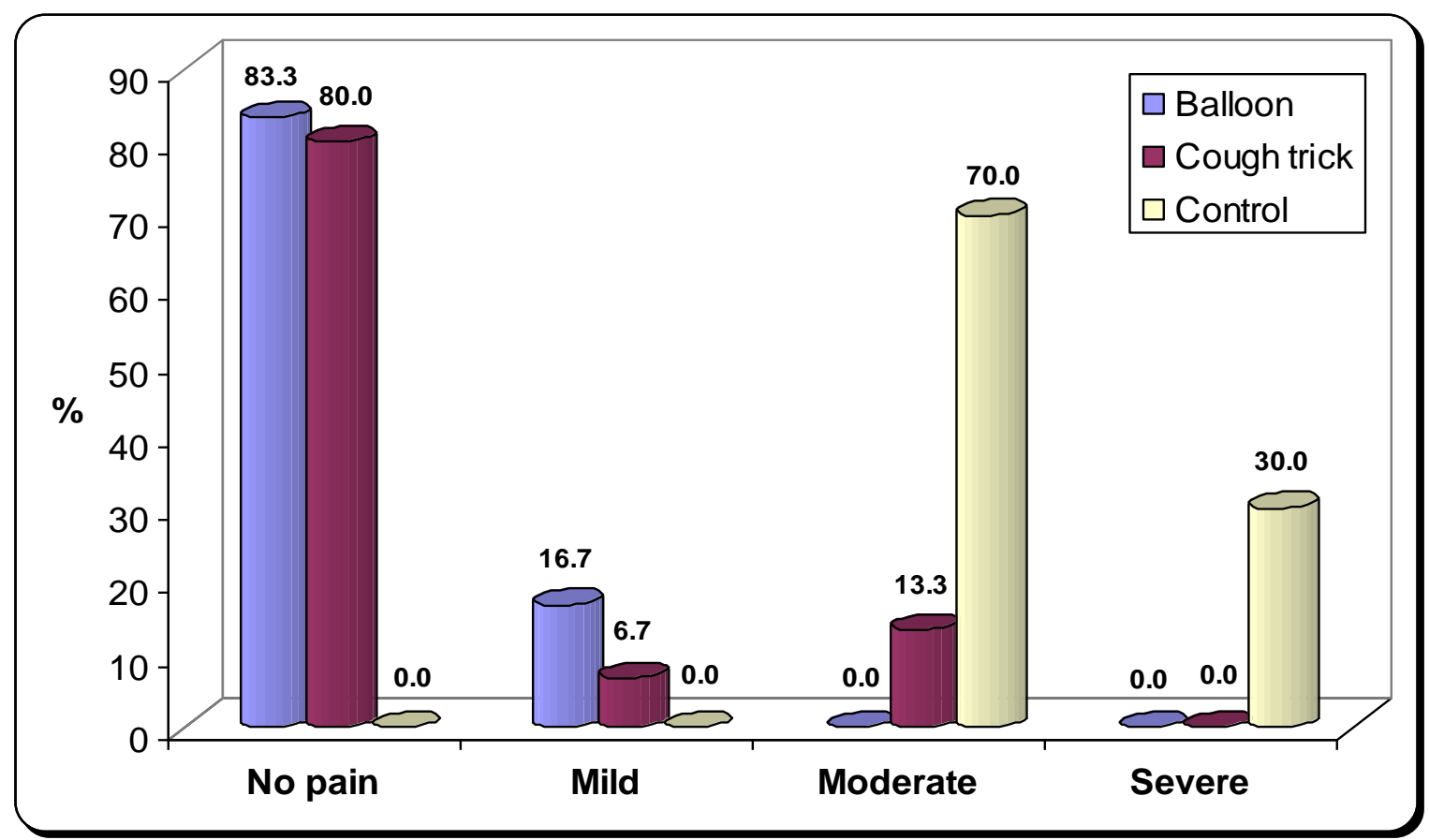

Figure (1): Comparison between balloon, cough trick and control groups regarding the pain level

Table (3): Difference between mean score of studied children's pain during venipuncture for the study group I and II according to their pain FPS-R scale ( $n=60)$.

\begin{tabular}{|l|c|c|c|}
\hline \multicolumn{1}{|c|}{ Items } & $\begin{array}{c}\text { Study group (I) } \\
\mathbf{n = 3 0}\end{array}$ & $\begin{array}{c}\text { Study group (II) } \\
\mathbf{n = 3 0}\end{array}$ & \multirow{2}{*}{ P-value } \\
\hline Mean \pm SD & $0.47 \pm 1.14$ & $1.00 \pm 2.15$ & \multirow{2}{*}{0.576} \\
\hline Median (Range) & $0.0(0.0-4.0)$ & $0.0(0.0-6.0)$ & \\
\hline
\end{tabular}


Table (4): Relationship between degree of facial pain scale revised and their gender in study groups (I \& II) and control group during venipuncture $(n=90)$.

\begin{tabular}{|c|c|c|c|c|c|c|}
\hline \multirow{3}{*}{ Items } & \multirow{3}{*}{ degree of pain } & \multicolumn{4}{|c|}{ Child gender } & \multirow{3}{*}{ P-value } \\
\hline & & \multicolumn{2}{|c|}{ Male } & \multicolumn{2}{|c|}{ Female } & \\
\hline & & No. & $\%$ & No. & $\%$ & \\
\hline \multirow{4}{*}{ Balloon group } & No pain & 13 & 92.9 & 12 & 75.0 & \multirow{4}{*}{0.336} \\
\hline & Mild & 1 & 7.1 & 4 & 25.0 & \\
\hline & Moderate & 0 & 0.0 & 0 & 0.0 & \\
\hline & Severe & 0 & 0.0 & 0 & 0.0 & \\
\hline \multirow{4}{*}{ Cough trick group } & No pain & 11 & 91.7 & 13 & 72.2 & \multirow{4}{*}{0.359} \\
\hline & Mild & 0 & 0.0 & 2 & 11.1 & \\
\hline & Moderate & 1 & 8.3 & 3 & 16.7 & \\
\hline & Severe & 0 & 0.0 & 0 & 0.0 & \\
\hline \multirow{4}{*}{ Control group } & No pain & 0 & 0.0 & 0 & 0.0 & \multirow{4}{*}{1.000} \\
\hline & Mild & 0 & 0.0 & 0 & 0.0 & \\
\hline & Moderate & 11 & 73.3 & 10 & 66.7 & \\
\hline & Severe & 4 & 26.7 & 5 & 33.3 & \\
\hline
\end{tabular}

Table (5): Relation between degree of facial pain scale revised and their age in study groups (I \& II) and control group during venipuncture $(n=90)$.

\begin{tabular}{|c|c|c|c|c|c|c|c|c|}
\hline \multirow{3}{*}{ Items } & \multirow{3}{*}{ degree of pain } & \multicolumn{6}{|c|}{ Child age } & \multirow{3}{*}{ P-value } \\
\hline & & \multicolumn{2}{|c|}{$6-<8$} & \multicolumn{2}{|c|}{$8-<10$} & \multicolumn{2}{|c|}{$10-12$} & \\
\hline & & No. & $\%$ & No. & $\%$ & No. & $\%$ & \\
\hline \multirow{4}{*}{ Balloon group } & No pain & 16 & 94.1 & 9 & 69.2 & 0 & 0.0 & \multirow{4}{*}{0.138} \\
\hline & Mild & 1 & 5.9 & 4 & 30.8 & 0 & 0.0 & \\
\hline & Moderate & 0 & 0.0 & 0 & 0.0 & 0 & 0.0 & \\
\hline & Severe & 0 & 0.0 & 0 & 0.0 & 0 & 0.0 & \\
\hline \multirow{4}{*}{$\begin{array}{l}\text { Cough trick } \\
\text { Group }\end{array}$} & No pain & 17 & 89.5 & 6 & 75.0 & 1 & 33.3 & \multirow{4}{*}{0.060} \\
\hline & Mild & 1 & 5.3 & 1 & 12.5 & 0 & 0.0 & \\
\hline & Moderate & 1 & 5.3 & 1 & 12.5 & 2 & 66.7 & \\
\hline & Severe & 0 & 0.0 & 0 & 0.0 & 0 & 0.0 & \\
\hline \multirow{4}{*}{ Control group } & No pain & 0 & 0.0 & 0 & 0.0 & 0 & 0.0 & \multirow{4}{*}{0.518} \\
\hline & Mild & 0 & 0.0 & 0 & 0.0 & 0 & 0.0 & \\
\hline & Moderate & 16 & 76.2 & 4 & 57.1 & 1 & 50.0 & \\
\hline & Severe & 5 & 23.8 & 3 & 42.9 & 1 & 50.0 & \\
\hline
\end{tabular}

Table (1): Indicates personal data of studied children. This finding revealed that more than half of studied children $(53.3 \%$ \& $60.0 \%$ respectively) in study group I \& II were female and only half $(50.0 \%)$ of children in control group were female and male. It was also found that more than half $(56.7 \% \& 63.3 \%)$ $\&$ more than two thirds $(70 \%)$ of children in study and control groups respectively were in age group (6 $-<8)$ years with a non significant $\mathrm{p}$ - value $(0.245)$. Regarding children's birth order, it was observed that, about half of them $(53.3 \% \& 46.7 \%$ respectively) in study group I \& II was the second child while less than half $(46.7 \%)$ of them in the control group was first child. Also less than two thirds $(63,3 \%)$ of study group II and control group \& more than two thirds $(70.0 \%)$ of them in study group I were from urban area. It was found that, mothers were accompanying the child $(73,3 \%, 86.7 \%$ \& $100.0 \%$ respectively) among both two study and control groups. The three groups had matchable regarding all personal data, age, gender, birth order, residence and parents' attendance during venipuncture.

Table (2): Represents percentage distribution of studied children regarding to their data related to venipuncture procedure. It was found that, more than one third $(36.7 \%)$ in control group \& less than one quarter $(10.0 \% \& 20.0 \%$ respectively) in study group I \& II had $1<4$ months time elapsed since the last blood sample. Regarding venipuncture site, it was observed that $(50.0 \% \& 60.0 \%$ respectively in study group I \& II and more than one third (36.7\%) in control group use basilic vein with p- value $(0.016 \&$ 0.010 respectively). Also the majority of them 
(90.0\%, $86.7 \%$ \& $80.0 \%$ respectively) used syringe 3 $\mathrm{cm}$ in all three groups.

It was noted that $(80.0 \%, 66.7 \%$ \& $70.0 \%$ respectively) in groups I, II \& III had success venipuncture from $1^{\text {st }}$ time. It was also found that, half of them were hospitalized because of blood diseases in control group while less than half $(43.3 \%$ \& $40.0 \%$ ) of them in studied groups I \& II were hospitalized because of gastrointestinal and blood diseases. Finally, it was observed that majority of studied children $(96.2 \%, 100.0 \%$ \& $100.0 \%)$ in groups I, II \& control group fear of needle due to hospitalization. The groups had matchable regarding data related to venipuncture procedure.

Figure (1): Demonstrates difference between the degree of studied children's pain for both two study \& control groups during venipuncture (balloon and cough trick groups). It was found that, $(83.3 \%$, $80.0 \% \& 70.0 \%$ respectively) of studied' children have mild pain in study group I \& II and moderate pain in control group. While children in study group I $\&$ II don't have any sever pain experience compared to less than one third $(30 \%)$ of them in control group.

Table (3): In spite of the significant difference wasn't illustrated regarding the degree of facial pain scale revised and their distraction methods (balloon and cough trick ) during venipuncture $(\mathrm{p}=0.576)$ but the mean \pm SD of studied children who inflated the balloon was lower than $(0.47 \pm 1.14)$ those who were doing cough trick methods $(1.00 \pm 2.15)$

Table (4): Illustrates relation between studied children gender and degree of pain. It was noticed that, there were no statistically significant differences between degree of pain and studied children's gender among three groups.

Table (5): Illustrates relation between studied children's age and degree of pain. It was noticed that there were no statistically significant relation between degree of pain and studied children's age among three groups.

\section{Discussion}

Venipuncture and venous cannulation are among the most invasive and painful procedures used to treat hospitalized children and are possibly the most common cause of anxiety and distress. Distraction is a technique for pain relief and should be considered due to applicability, easiness of use and easiness of implementation (Craig, 2016).

The results of the current study revealed that school age children who had not been directed in a painrelieving intervention experienced as moderate and severe pain during venipuncture as illustrated in figure (1). This was consistent with Birsen, (2015) who conducted a similar study related to the effect of balloon inflation and cough trick method on easing pain in children during the drawing of venous blood samples and found that control group had experience sever pain during drawing of samples. Also the current study showed that majority of studied children experienced mild pain during venipuncture in study groups compared to none in control group. Our result agree with that of Mohammad et al., (2017), who showed that balloon inflation and cough trick methods was effective in reducing pain during venous blood drawing in children. This may be due to distraction with balloon inflation and cough trick causes attract the attention of the child away from pain stimuli during a medical procedure. Therefore, as a distraction method, balloon inflation and cough trick might be useful for decreasing pain and anxiety during medical procedures.

Our results revealed that, the majority of studied children in the balloon group have mild pain compared to none in control group, also about one third of children in control group have severe pain compared to none in the balloon group and the mean pain intensity in a balloon group was $0.47 \pm 1.14$ while that in control group was $7.67 \pm 1.75$ as shown in figure (1) \& tables (3). These results were consistent with Serap, (2015) who reported that balloon group had significantly lower pain levels than control group during venipuncture. It also agreement with Mohamed, (2016) who studied comparison of the effectiveness of buzzy, distracting cards and balloon inflating on mitigating pain and anxiety during venipuncture in a pediatric emergency department and they found that the mean pain intensity in balloon group significantly lower than that in control group.

The results of present study showed that both methods of balloon and cough trick reduced children's pain. In spite of significant difference was not illustrated regarding the degree of children's pain experience between balloon inflation \& cough trick methods Table (3). The percentage of children who were suffering from mild pain \& inflated balloon was higher than those who were suffering from mild pain $\&$ did cough trick methods. So it could be said that balloon inflation is slightly better than cough trick methods. these results were in agreement with Serap, (2015), who cited that the effect of balloon on reducing the pain intensity was higher than cough trick group. However, it contradict with Wallace \& Allen, (2015), they found that the balloon inflation and cough trick methods were equally effective in reducing pain during the procedure of drawing venous blood in children between 9 and 12 years of age. The finding of this study indicated that both methods can be used in different painful procedures and should be supported by more evidence-based studies with different age groups. 
According to the findings, there was no statistically significant relation between pain and gender in all groups during venipuncture Table (4). This result go on line with Rahmanian et al., (2016), who studied the effect of distraction in the two groups of inflating the balloon and mother's armson on pain during venipuncture and they found that there were no statistically significant differences between the both sexes in the study and control groups. However it contradict with other studies which reported differences in expressions of pain during invasive procedures between girls and boys, and also contradict with Urden, et al., (2012), who noted that females' pain threshold is lower than male.

As found in the study findings, there were no statistically significance differences between the pain score level and child's age in all groups during venipuncture Table (5). This result goes on line with Becky, (2015) who found that no statistically significant relation was observed between age and severity of pain associated with venipuncture. In contrary to other study which was reported by Karen, (2017) who noted that there were statistically significant differences between the pain level and child 'age.

\section{Conclusion}

Based on the results of the present study, it could be concluded that balloon inflation and cough trick methods were effective in reducing pain during the procedure of drawing venous blood sample among children. It is proved from this study that balloon inflation was slightly better than cough trick method in pain relief for children during venipuncture.

\section{Recommendations}

Based on the results of the current study, the following recommendations are suggested:

1. Educational programs should be provided to increase knowledge and skills of health care professional particularly new nurses in applying non-pharmacological intervention such as cough trick to reduce pain intensity in children during any invasive procedures and also teach it to parents and encourage using with each venipuncture experience.

2. Pediatric nurses should be encouraged to use the appropriate non-pharmacological intervention e.g cough trick and balloon inflation to reduce the intensity of pain among children during any invasive procedures.

3. Cough trick is recommended to be used as standard care technique for reduction of pain among children during the venipuncture also cost-effective and have no complications and can be performed with an easy workout
4. Further research should be replicated and expanded to include a larger sample, focusing on outcomes with different children populations undergoing a variety of procedures in various settings.

\section{References}

1. Algren J., \& Goldman R., (2012): Nonpharmacologic techniques for the management of pediatric pain, Pediatric pain management for primary care, Management Nursing Journal, 11(2): 90-95.

2. American Academy of pediatrics (AAP, 2011): The Assessment and Management of Acute Pain in Infant, Children, and Adolescents, US National Library of Medicine, 108(3): 793799.

3. Anand B., \& Craig A., (2014): New perspectives on the definition of pain, Pain, Published by Elsevier Inc, 67(1): 3-6.

4. Becky H., (2015): Using distraction to reduce venipuncture pain and distress in school aged children, Master thesis of Health Science in the University of Canterbury: 575-582.

5. Birsen M., (2015): Effects of balloon inflation and cough trick methods on easing pain in children during the drawing of venous blood samples, Journal for Specialists in Pediatric Nursing, 2(1): 22-25.

6. Craig K., (2016): The construct and definition of pain, edited by Tim Oberlander \& Frank J. Symons (Baltimore, USA: Paul H. Brookes Publishing Co, 17-18.

7. Francesco A., Jennifer, Z., Jennifer, A., \& Sandra, M., (2013): Reliability and validity of the Facial Pain Scale - Revised in assessing acute pain in critically ill patients, American Journal of critical care, 19 (1): 55-61.

8. Hsieh, (1998): power calculation between means of two independent groups, NewsMedical Life Sciences.

9. Karen W., (2017): A study on the effect of distraction techniques on the pain of venipuncture in children, Health and Quality of Life Outcomes Journal, 16(59): 1-9.

10. McGrath J., \& Frager H., (2017): Psychological interventions for needle related procedural pain and distress in children and adolescents. Cochrane Database of Systematic Reviews, Vol.(127) ,Issue 1,PP.1-9.

11. Mohamed, (2016): Comparison of the effectiveness of buzzy, distracting cards and balloon inflating on mitigating pain and anxiety during venipuncture Journal of Pediatric Nursing, 4(1),1-9. 
12. Mohammad S., Amir H., Azar J., \& Masoumeh B., (2017): The effect of distraction techniques on the Pain of venipuncture in Children: A Systematic Review, Journal of Pediatrics Review, 5 (1), 1-11.

13. Mutlu B., \& Balcı S., (2015): Effects of balloon inflation and cough trick methods on easing pain in children during the drawing of venous blood samples: a randomized controlled trial. Journal for Specialists in Pediatric Nursing, 20(6): 178186.

14. Nilsson S., Finnström B., \& Kokinsky E., (2008): The FPS-R behavioral scale for procedural pain assessment in children aged 516 years, Paediatr Anaesth Journal,Vol.18(8),pp.767-774.

15. Rahmanian E., Mohammad S., \& Sanie N., (2016): The effect of distraction in the two groups of inflating the balloon and mother's armson on pain during venipuncture, International Journal of medical research, 5(1):331-335.

16. Serap B., (2015): Effects of balloon inflation pain intensity in children during the drawing of blood samples, Elservier, 108(3), 93-99.

17. Sukhomlinova T., \& Tichonovskay S., (2013): Essentials of pediatric nursing, pain management in children, chapter 14, 2nd edition, Lippincott Williams \& Wilkins, pp.553591.

18. Urden L., Stacy K., \& Lough M., (2012): Critical Care Nursing: Diagnosis and Management, 6th ed, Missouri Mosby, pp. 211225.

19. Wallace D., \& Allen K., (2015): The "cough trick:" a brief strategy to manage pediatric pain from immunization injections. Pediatrics, 125(2): 367-373. 